\title{
"DXemon Juice:" Analytical Evaluation of an Extraction Process for the Purification and Freebasing of Dextromethorphan from Cold Preparations
}

Dear Editor,

Abuse of dextromethorphan in cold medications has become an increasingly common problem in the US [1]. I recently reported a case of dextromethorphan toxicity in which the patient performed an acid base extraction to freebase and purify the dextromethorphan from the other constituents in the cold medication [2]. Two extraction techniques are available on the Internet, a single-phase, acid-base extraction that results in a powder (i.e., Crystal Dex) or a 2-phase acid-base extraction that results in a liquid (i.e., DXemon juice) [3]. Both techniques reportedly are used to allow users to feel the effects of dextromethorphan without the side effects of antimuscarinic agents, saccharin, guaifenisen, and additives that are commonly found in combination cold preparations.

I wondered whether this technique eliminated the other pharmaceuticals in combination cold preparations or if there may be remaining decongestants, antihistamines, or acetaminophen in the end product. For that reason, I performed the 2-phase acidbase extraction as instructed on the Internet and previously described [2]. The extraction was performed using the equipment suggested on the Internet [3]. The initial product was $295 \mathrm{~mL}$ ( $10 \mathrm{oz}$ ) of Vicks NyQuil Brand Multi-Symptom cold/flu relief (contents: $295 \mathrm{mg}$ dextromethorphan, $9.83 \mathrm{~g}$ acetaminophen, $123 \mathrm{mg}$ doxylamine, $590 \mathrm{mg}$ pseudoephedrine). A total of 300 $\mathrm{mL}$ of household ammonia was added and vigorously shaken for 5 minutes, then $133 \mathrm{~mL}$ ( $4.5 \mathrm{fl} \mathrm{oz}$ ) of Zippo brand lighter fluid (naphtha) was added and shaken for another 5 minutes. The mixture was allowed to separate and the hydrophilic ("water") layer discarded. The hydrophobic ("oily") layer was washed with 150 $\mathrm{mL}$ of room-temperature water, allowed to separate, and the hydrophilic layer discarded again. A total of $250 \mathrm{~mL}$ of lemon juice was added, mixed for 5 minutes, allowed to separate, and the hydrophobic layer discarded. The extraction produced 233 $\mathrm{mL}$ of light pink liquid with the faint smell of naphtha. GC/MS was performed and reported the following: Dextromethorphan $600 \mu \mathrm{g} / \mathrm{mL}$ (total $139 \mathrm{mg}$ ), acetaminophen $48.9 \mu \mathrm{g} / \mathrm{mL}$ (total $11.4 \mathrm{mg}$ ), doxylamine $160 \mu \mathrm{g} / \mathrm{mL}$ (total $37.3 \mathrm{mg}$ ), and pseudoephedrine $0 \mu \mathrm{g} / \mathrm{mL}$ (total $0 \mathrm{mg}$ ).

This crude extraction yielded only $47 \%$ dextromethorphan, $30 \%$ doxylamine, and negligible amounts of acetaminophen and pseudoephedrine. Although there is little risk of acetaminophen or pseudoephedrine toxicity with ingestion of this product, dextromethorphan and doxylamine remain in intoxicating doses.

Robert G. Hendrickson, MD

3181 SW Sam Jackson Park Road, CSB 550

Portland, OR 97239

E-mail: hendriro@ohsu.edu. 5034949495.

\section{REFERENCES}

1. Burda A, Razo M, Wahl M. Rising abuse of Coricidin over a three-year period. J Toxicol/Clin Toxicol 2004;42(5):757.

2. Hendrickson RG, Cloutier R. "'Crystal Dex': Free-base Dextromethorphan." J Emerg Med 2007;32(4):393-396.

3. Erowid [webpage on the Internet]. DXM Chemistry and Extraction [updated 24 Apr 2007; cited 27 Feb 2008). Available from: http://www.erowid.org/chemicals/dxm/faq/dxm_ chemistry.shtml\#toc. 11.1 